\title{
Mexico - Measures Affecting Telecommunications Services (WT/DS204/R) A Comment on "El mess in TELMEX”
}

\author{
DAMIEN J. NEVEN* \\ Graduate Institute of International Studies, Geneva and \\ Centre for Economic Policy Research, London \\ PETROS C. MAVROIDIS* \\ Columbia Law School, New York and University of Neuchâtel, Switzerland
}

\section{Introduction}

This chapter reviews the panel report on Mexico - Measures Affecting Telecommunication Services. The Panel considered claims by the United States that Mexico acted inconsistently with its obligations in respect to the liberalization of its market for telecommunication services. It is the first Panel to consider solely the rules agreed upon in the General Agreement on Trade in Services (GATS). It is also the first Panel to deal with the telecommunication services industry and its complex layers of legislation, in particular the rules agreed to in the Telecommunications Reference Paper (TRP) on pro-competitive regulatory principles. Viewed from this perspective, this report is, because of its potential as a precedent, of particular significance.

This case essentially revolves around the question of under what conditions foreign telecom operators can terminate calls in Mexico. The United States argued that the Mexican regulation of termination charges was not in conformity with the obligations contained in the TRP. It argued in particular that the termination charges were not cost-oriented and that Mexico had set up a cartel of telecom operators.

* This chapter was prepared in the context of the project of American Law Institute project on the Principles of World Trade Law. We would like to thank Joseph Weiler, Aaditya Mattoo, Pierre Larouche, Gary Horlick, Henrik Horn, Alan Sykes, and Damien Gérardin for useful comments on a previous version of this chapter. 
The following section of this chapter, Section 2, briefly discusses the Mexican regulation in dispute from an economic perspective and presents the legal framework of the dispute, focusing on the relevant provisions of the TRP. Section 3 analyzes whether and how the termination charges can be covered by the TRP. In this section, we first observe that the US operators do not supply cross-border services under mode 1, as the Panel stated in its report. Indeed, a cross-border (mode 1) supply of telecom services can hardly take place when both the supplier (a US telecom firm) and the consumer of the service (US subscribers) are situated in the same jurisdiction (as is the case here). Finding, as the Panel did, that US firms were supplying crossborder (mode 1) services does not accord with the basic definition of a mode-1 service. Rather, a southbound international call involves the purchase by US operators of termination services from Mexican carriers. Hence, the only cross-border transaction here is a transaction involving the sale of termination services by Telmex (the Mexican carrier asked to terminate southbound calls) to its North American clients (the US operators requesting termination of their calls in the Mexican market). The transaction involves Mexico exporting services, rather than the other way around. Second, we observe that Mexico did not enter into any commitment with respect to the export of termination services (under Art. XVIII GATS). Third, we discuss the issue of whether the Panel, had it properly defined the sales of termination services as a mode-1 export, could have imposed the disciplines of the TRP on the supply of that service. In this event, the Panel would possibly have taken the position that the TRP prevents the exercise of market power in export markets. We argue that such an approach would not be warranted: we find, with respect to both wording and context, that the TRP does not apply to cross-border supply of services but to mode-3 supply of services only.

Assuming, for the sake of argument, that termination charges for international calls are covered by the TRP, Section 4 discusses whether the termination fees charged by Telmex can be considered as costoriented. We argue that the Panel defined a benchmark for cost orientation, namely long-run average incremental cost, that is somewhat controversial. There are indeed a number of good reasons against the adoption of this standard, and it is surprising that a WTO panel, with no particular expertise or experience in this matter, should take responsibility for imposing a particular regulatory standard in such a complex field. 
Section 5 discusses whether cartels fall within the scope of the TRP. We argue that the TRP should not be construed as containing an obligation with respect to cartels. Section 6 contains a brief summary of our findings and some conclusions.

\section{Background}

\subsection{Regulation of termination charges}

Within Mexico, local networks (the "last mile") are typically provided by the historic incumbent monopolist (Telmex). Long-distance services within Mexico (between cities or regions) have been opened to competition, and, at the time of the instant case, there were as many as 27 long-distance carriers operating in the country, including Telmex. Long-distance carriers could not, however, be controlled by foreign operators, ownership being limited to a $49 \%$ share (according to the Mexican telecom regulation, in line with appropriate specific limitations on commitments taken by Mexico within GATS). Nonetheless, some carriers were still partly owned by US operators or associated with them.

In this environment, the completion of international calls requires the linking of networks operated by different firms. ${ }^{1}$ In order to offer outgoing calls to the United States, for instance, long-distance carriers in Mexico must connect to a firm operating in the United States. Similarly, in order to provide international service to their domestic subscribers, US operators need a connection to a Mexican operator in order to terminate the calls. From an economic point of view, the Mexican and US legs of an international call can be seen as strict complements; a call originating in the United States up to the Mexican border has no value if it is not associated with a Mexican termination; conversely, a call originating in Mexico up to the US border has no value, unless it is associated with a termination in the United States.

The connection between US and Mexican networks is subject to a specific regulation, referred to as the International Long Distance (ILD) rules. ${ }^{2}$ We first describe these rules and subsequently discuss their economic significance.

${ }^{1}$ Given that, in addition, none of the Mexican carriers control a foreign network.

2 "Rules for the provision of international long-distance service to be applied by the licensees of public telecommunications networks authorized to provide this service." 


\subsubsection{ILD rules}

This regulation includes, for the purpose of our discussion, four important components:

First, it establishes a system of authorization/certification for the operation of the switches that connect domestic and foreign networks. These are referred to as international gateways. At the time of this case, there were 11 international gateways, which were operated by the Mexican long-distance carriers. That is also to say that some longdistance carriers did not operate an international gateway and had to subcontract the switching of their international calls to a carrier operating a gateway.

Second, the regulation stipulates (Rule 2, XII) that all gateway operators should charge the same rate for terminating calls in Mexico, referred to as the "settlement rate." Termination involves two separate operations, namely the international switch and the connection to the Mexican subscriber. The latter involves a local link and possibly a long-distance link. ${ }^{3}$ The regulation also specifies that the same rate will apply, regardless of whether the international gateway operator terminates the call itself or transfers the call to another long-distance (and/or local) carrier. A symmetric pricing scheme is stipulated for outgoing calls: foreign operators must be paid a fixed fee for the termination of calls in their territory. Again, this fee is not dependent on the carrier that originates the call in Mexico.

Third, the regulation (Rule 13) determines how the (uniform) prices (for terminations in Mexico and abroad) are set; the Mexican operator with the largest market share of outgoing calls in a reference period is put in charge of negotiating the rates with the foreign operators. At the time of the instant case, Telmex had (by a wide margin) the highest market share and thus was in charge of negotiating termination fees.

Fourth, the regulation (Rule 2, XIII) allocates incoming calls among the international gateways. Each gateway operator has an allocation of incoming calls for any given month, which reflects its market share of outgoing calls during the previous month. If an operator receives calls in excess of its quota, it must redirect calls to other gateway operators

3 The gateway operator is supposed to pay to the operator of the local loop an interconnection fee, which corresponds to the interconnection fee that is normally paid for national calls, as well as some (unspecified) percentage of the settlement rate. 
in order to achieve the appropriate distribution of market share. In such a case, the termination charge that the gateway operator receiving the call has obtained from the foreign operator is passed through to the gateway operator to whom the call is transferred (less a fee that reflects the cost of switching and routing).

\subsubsection{Some consequences of the ILD rules}

From an economic perspective, the consequences of this regulation can be outlined as follows:

First, since no US firms can terminate calls in Mexico or control a gateway operator, all US operators must purchase termination from a Mexican operator when offering a call from the United States to Mexico.

Second, the price of termination services within Mexico is set in such a way that it is likely to mimic the price that would be set by a monopolist; the regulation envisions that the price is determined by a single firm (Telmex), with the knowledge that all others will apply the same price. The incentives of the firm in charge of setting the price will then mimic the incentives that a monopolist would have, at least if the share of overall demand that the firm can obtain is independent of the price. From this perspective, the market-sharing arrangement that supplements the pricing arrangement, in such a way that market shares are determined by shares in another market, is instrumental and indeed brings the incentives of Telmex closer to those of a monopolist in the pricing of termination services. Some discrepancies may still arise to the extent that termination services are differentiated or to the extent that the marginal costs of the different operators vary. In those circumstances, a hypothetical firm in charge of maximizing the overall profit (a monopolist) may want to differentiate prices among operators. The regulation envisages a single price and may thus fall short of maximizing the overall profit. Finally, the market-sharing arrangement on the basis of market shares in outgoing calls also consolidates the implementation of the monopoly solution, as it removes the incentives for secret price cuts with respect to the termination of incoming calls.

Third, the pricing of termination and allocation of incoming calls will affect incentives in the market for outgoing international calls. The profitability of a reduction in price in this market will be enhanced 
at the margins, and hence the regulation should lead to lower prices for outgoing international calls.

Fourth, the regulation also enforces a monopsony in the market for termination of calls in the United States. US operators face a single buyer. The classic theory of monopsony indicates that a single buyer will internalize the effect that an increase in the price paid for a marginal unit will have on infra-marginal ones, and, hence, will buy less than what would be purchased by a collection of small independent buyers. The classic theory of monopsony, however, assumes that the single buyer faces a well-defined supply curve. Under the circumstances, it may be more reasonable to assume that there is a relatively small group of firms selling termination services in the United States. ${ }^{4}$ How the outcome of bargaining over termination rates will be affected by the presence of a few buyers, rather than a large collection of them, will vary depending upon the details of the bargaining. But it seems reasonable to presume that the implementation of a monopsony will lower the price of termination in the United States (relative to the price that would obtain with a set of independent buyers).

Fifth, the regulation clearly affects the incentives that US operators have to enter into agreements with Mexican firms, and in particular with Telmex, with respect to the routing of calls; US operators will be more or less indifferent regarding different Mexican partners with respect to calls into Mexico. Indeed, they will be charged the same price, regardless of the gateway operator that they choose. Neither can their choice be driven by quality considerations, as they have no control over the identity of the operator that will effectively terminate the call. Matters are different, however, with respect to the termination of calls into the United States. In this regard, agreements with larger Mexican operators are more attractive; even if the prices paid for termination in the United States will not vary from one operator to another, total revenues will increase in line with the volume of calls handled by the Mexican operator with whom they enter into an agreement. Mexican operators, however, are fairly indifferent as to their choice of a US partner: the market-sharing agreement for termination of calls from the United States effectively ensures that the total revenue they obtain

${ }^{4}$ According to Sidak and Singer (2004), the US market is highly concentrated, with an HHI index around 5000 during the 1990s (5842 in 1992, declining to 4162 in 1999, but increasing again to 6215 in 2000). 
is not dependent on the size of their US partner. As indicated above, it is effectively determined by each operator's domestic market share. Hence, large Mexican operators are in a privileged position. They are attractive to US partners but have no marked preference for a particular US partner. They should accordingly be in a position to extract a high surplus for entering into a routing agreement. Interestingly, it would appear that it was a conflict between the US operators with respect to the choice of the Mexican partners that led to the dispute in the first place. According to Mardsen (2004), Sprint (a relatively small US operator) entered into a routing agreement with Telmex in the mid 1990s. AT\&T and MCI had to settle for smaller Mexican partners and were dissatisfied with this outcome. According to Mardsen (2004), they called on the US Trade Representative (USTR) to help them gain better access. It is somewhat intriguing, however, that the United States did not directly challenge the practice that disadvantaged AT\&T and MCI, relative to Sprint, namely the buyers' cartel: Telmex fixing the price at which termination in the United States would be bought by all Mexican operators. Rather, the United States challenged the export cartel, namely the cartel with respect to the export of termination services (such that Telmex would fix the price that applied to sales of termination services by all Mexican operators to US telecom firms). One can only conjecture that the United States anticipated that it had a stronger case against the export cartel than the buyers' cartel, and presumed that prohibition of the export cartel would also trigger the dissolution of the buyers' cartel.

\subsection{The legal framework}

For the Panel to find against Mexico, it first had to establish that the transaction at hand was covered by Mexico's commitments. In the GATS $^{5}$ framework, the obligations assumed by WTO Members are distinguished between general obligations and specific commitments. The former binds every WTO Member irrespective of specific commitments, whereas the latter reveals the extent of trade liberalization assumed. Mexico, for example, by virtue of the most-favored-nation clause (a general obligation), must, in principle, treat all telecoms operators originating in any WTO Member in a non-discriminatory manner.

\footnotetext{
${ }^{5}$ GATS stands for General Agreement on Trade in Services.
} 
Were Mexico, however, to decide not to undertake any specific commitment in the field of telecoms, this contractual promise would amount to an empty shell (in terms of trade liberalization), since Mexico will be consistently honoring its promise by refusing access to all nonnational-telecom carriers to its telecom market. Similarly, with respect to market access (Art. XVI GATS), WTO Members are committed to "accord services and service suppliers of any other Member treatment no less favorable than that provided for under the terms, limitations and conditions agreed and specified in its Schedule." In addition, according to Art. XVIII GATS, "Members may negotiate commitments with respect to measures affecting trade in services not subject to scheduling under Art. XVI .... Such commitments shall be inscribed in a Members' schedule." One hundred and fourteen WTO Members so far (counting the European Union members individually) have undertaken specific commitments in the field of telecommunications.

The WTO Members that have entered commitments must respect a complicated set of obligations. Besides the GATS, they will have to respect the following legal documents: (i) the Annex on Telecommunications; (ii) the regulatory principles reflected in the TRP; and (iii) the schedules of specific commitments.

Legally speaking, by virtue of Art. XXIX GATS, the Annexes to the GATS are an integral part of the GATS. Furthermore, by virtue of Art. XX. 3 GATS, the specific commitments entered into by WTO Members are an integral part of the GATS as well. The legal nature of the TRP is more convoluted. It was agreed to by the negotiators as a necessary step to further specify the obligations reflected in the other legal instruments. However, WTO Members did not have to adopt it as such. As a result, some did, some did not, and some adopted a portion of it. Consequently, there are many national "TRPs" with no identical content. To the extent adopted, a national TRP is part of a given WTO Member's commitments. So far 69 WTO Members have adopted the TRP either in toto or in part. The regulatory principles reflected in the TRP have been inscribed in schedules of specific commitments in accordance with Art. XVIII GATS (additional commitments).

The United States presented claims under both the Annex and the TRP. Because the TRP in any event incorporates the obligations reflected in the Annex, in the remaining part of the chapter we will focus on the claims made by the complainant under the TRP. There are three important sections of the TRP for the purposes of 
our discussion. First, the reference paper defines a "major supplier" in the following terms:

A major supplier is a supplier which has the ability to materially affect the terms of participation (having regard to price and supply) in the relevant market for basic telecommunications services as a result of:

(a) Control over essential facilities; or

(b) use of its position in the market.

Second, Section 1 relates to competitive safeguards and reads as follows:

1.1. Prevention of anti-competitive practices in telecommunications Appropriate measures shall be maintained for the purpose of preventing suppliers who, alone or together, are a major supplier from engaging in or continuing anti-competitive practices.

1.2. Safeguards

The anti-competitive practices referred to in the above paragraph shall include in particular:

(a) Engaging in anti-competitive cross-subsidization;

(b) using information obtained from competitors with anticompetitive results; and

(c) not making available to other services suppliers on a timely basis technical information about essential facilities and commercially relevant information which are necessary for them to provide services.

Third, Section 2 focuses on interconnection and in relevant part reads as follows:

2. Interconnection

2.1. This section applies, on the basis of the specific commitments undertaken, to linking with suppliers providing public telecommunications transport networks or services in order to allow the users of one supplier to communicate with users of another supplier and to access services provided by another supplier.

2.2. Interconnection to be ensured

Interconnection with a major supplier will be ensured at any technically feasible point in the network. Such interconnection is provided:

(a) Under non-discriminatory terms, conditions (including technical standards and specifications), and rates and of a quality no less favourable than that provided for its own like services or for like services of non-affiliated service suppliers or for its subsidiaries or other affiliates; 
(b) in a timely fashion, on terms, conditions (including technical standards and specifications), and cost-oriented rates that are transparent, reasonable, having regard to economic feasibility, and sufficiently unbundled so that the supplier need not pay for network components or facilities that it does not require for the service to be provided; and

(c) upon request, at points in addition to the network termination points offered to the majority of users, subject to charges that reflect the cost of construction of necessary additional facilities.

The United States claimed that the ILD rules discussed above were inconsistent with the obligations Mexico assumed by virtue of its TRP. In particular, the United States claimed that:

(i) international termination of calls fell within the scope of Mexico's commitments with respect to "interconnections" under Section 2 of the TRP;

(ii) Telmex should be considered as a "major supplier";

(iii) the interconnection rates charged by Telmex (and other gateway operators) to US suppliers were not "cost-oriented"; and, finally,

(iv) Mexico failed to ensure that Telmex and other gateway operators did not engage in anti-competitive practices, as these firms operated a cartel.

The Panel effectively accepted all the US claims, albeit only with respect to facilities-based services. In June, Mexico decided not to appeal and agreed to remove disputed ILD rules. ${ }^{6}$ In effect, Mexico committed to a pricing of termination charges on the basis of commercial negotiations between US and Mexican operators. The United States was satisfied.

\section{Crossing the border?}

The United States focused its complaint on the termination in Mexico of calls originating in the United States. In order to evaluate whether

\footnotetext{
${ }^{6}$ WT/DS204/7 S/L/161. One can only offer conjectures as to why Mexico decided not to appeal. It would appear that the WTO ruling presented the Mexican government with an opportunity to liberalize the market (and reduce the power of Telmex) at limited political cost (the WTO being portrayed as an external constraint). The Mexican government (and its competition authorities) had previously tried to liberalize the market on their own initiative, but faced significant political pressures.
} 
Mexico had undertaken a commitment with respect to this service, the Panel first sought to define the service and its mode of supply.

\subsection{Mode-1 supply of basic telecommunications services}

The United States claimed that its operators were providing crossborder telecommunication services (mode 1). In the US argument, Mexico's practices were unlawful because they contravened Mexico's commitments with regard to mode-1 supply of "basic telecommunications services"7 from the United States to Mexico, through US carriers. This was taken for granted by the Panel. In $\S 7.42$ of its report, we read:

More generally, a supplier of services under the GATS is no less a supplier solely because elements of the service are subcontracted to another firm, or are carried out with assets owned by another firm. What counts is the service that the supplier offers and has agreed to supply to a customer. In the case of a basic telecommunications service, whether domestic or international, or supplied cross-border or through commercial presence, the supplier offers its customers the service of completing the customer's communications. Having done so, the supplier is responsible for making any necessary subsidiary arrangements to ensure that the communications are in fact completed. The customer typically pays its supplier the price of the end-to-end service, regardless of whether the supplier contracts with, or uses the assets of, another firm to supply the services.

This passage, which is contained under the heading "(b) Are the services at issue supplied cross-border?," appearing on page 144 of the Panel report, leaves no doubt that the Panel was indeed contemplating a transaction whereby a US carrier supplies cross-border telephone services to its customers, and not the sale of termination services from Mexico to the United States. Indeed, with respect to this latter element of the telephone service, the Panel makes the point that it is immaterial whether it is being subcontracted (out-sourced) by the US carrier.

The definition of mode 1 in GATS is not a model of clarity. However, the intention of the parties must be that the supplier of a service and its consumer are not physically present in the same territory.

\footnotetext{
${ }^{7}$ That is, public voice telephony, circuit-switched data transmission, and facsimile services, both "facilities based" and by a "commercial agency."
} 
This is what distinguishes mode 1 from the three other modes of supply. Article. I.2 GATS reads:

For the purposes of this Agreement, trade in services is defined as the supply of a service:

(a) from the territory of one Member into the territory of any other Member.

The Scheduling Guidelines (WTO Doc. MTN.GNS/W/164, dated September 3, 1993) underscore the need to ensure a common understanding of what each mode of supply covers and refer to telecoms as one means for supplying cross-border services from the supplier to the consumer:

It is important to have a common understanding of what each mode covers. To this end, further examples and explanations are given below.

(a) Cross-border supply

International transport, the supply of a service through telecommunications or mail, and services embodied in exported goods (e.g. a computer diskette, or drawings) are all examples of cross-border supply, since the service supplier is not present within the territory of the Member where the service is delivered.

Examples of cross-border supply offered either in the scheduling guidelines, or indeed in the actual schedules themselves, refer to transactions in which the supplier of the service and the consumer are physically present in two different territories, neither of them moves, and yet a service is being supplied. For example, an attorney at law established in Geneva, Switzerland, sends, by e-mail, his legal advice to a client who resides in Brussels, Belgium.

If one applies this line of reasoning to the transaction considered by the Panel, we are led to conclude that US operators do not provide a cross-border service under mode 1 , since both the supplier (US carrier) and the consumer (US residents) are indeed physically present in the same territory.

\subsection{Mode-1 export of services?}

As indicated above, an international call from the United States to Mexico can be seen as the bundle of two strict complements, namely a routing from the US subscriber to the border and a termination 
within Mexico. The US operator sells the bundle to a US subscriber and purchases one element of the bundle (one input) from a Mexican operator. From this perspective, Mexican operators are thus selling one service (termination) to a foreign firm. In other words, they are producing a service using domestic inputs and selling it to a foreign undertaking. ${ }^{8}$ This is literally a mode- 1 type of supply, but in this perspective the supplier is the Mexican operator that terminates the call (and not the US operator, as deemed by the Panel). ${ }^{9}$

Hence, the Panel ends up imposing a discipline on the exports of Mexican services, making sure in particular that such services are sold at prices that reflect cost. This raises at least two questions: first, it raises the question whether from a legal perspective the GATS framework imposes a discipline on exports. Second, it raises a fundamental question about the distinction between exports and imports in the case of telecom services. Indeed, the perspective that we have taken so far relies on what could be seen as a convention, namely that the consumer of a southbound call is the US subscriber.

The GATS allows for additional commitments with respect to exports under Art. XVIII. Some countries have indeed entered into additional commitments with respect to exports, in the case of maritime services, for instance. Mexico, however, has not entered into any commitment with respect to exports. Arguably, the Panel should have observed this and simply dismissed the case.

${ }^{8}$ This is a perfectly legitimate scenario in the GATS context: according to Art. XXVIII(i) GATS: "'service consumer' means any person that receives or uses a service" (emphasis added).

${ }^{9}$ One can also wonder whether US firms could be seen as supplying services in Mexico if they could open subsidiaries in Mexico that would complete the calls. In that circumstance, US firms would compete with domestic suppliers (for termination) and from that perspective, they could be seen as supplying services through mode 3 . Still, they would not be selling to Mexican customers, and at least from this perspective they could not be seen as exporting a service to Mexico. It is not clear to us whether both elements are required (the provision of a service in competition with domestic suppliers and the sale to a domestic customer). Anyhow, it is clear that Mexico has never committed to allowing US firms to open subsidiaries (as recognized by the Panel) and hence had not committed to allowing supply through mode 3 . Of course, if US firms were in addition allowed to sell outgoing calls in Mexico, they would clearly be offering a service through mode 3. This seems to imply that imports of telecom services can only be supplied through mode 3 and that supply requires an access to the local network for foreign firms, as well as the authorization to sell services domestically. This analysis, however, hinges on the principle that the calling party pays for the call. The issue is further discussed below. 
The Panel was thus set on a misleading course from the very beginning when it ruled that the US operators were supplying crossborder telecommunications services. The panel (§ 7.30) did not reflect on the nature of the services provided by the US operators and offered a superficial discussion of the modes of supply; the Panel was satisfied that a call originating in the United States was supplied cross-border simply because, according to the "ordinary meaning of words," it was "supplied from the territory of one member into the territory of another." The Panel did not pause to reflect on the fact that the ordinary meaning of words did not provide guidance with respect to the direction in which the services flowed.

Interestingly, the approach that we take here has actually been put forward in the context of the negotiation (as we discovered ex post). Had the Panel spent more time delving into the negotiating documents, it would have come across similar points of view. Australia, for example, tabled a proposal that is along the same lines. On page 4 of its proposal, ${ }^{10}$ we read:

Australia considers that cross-border supply applies to services such as telecommunications termination services whereby a service provider in the territory of one member delivers or terminates a telephone call to a service provider in the territory of another member. Under Article I of the GATS the service provider receiving the call is supplying a (termination) service to a service provider in another country.

As indicated above, the Mexican regulation allowed for the operation of a buyers' cartel (a cartel in the purchase of termination services in the United States) in addition to the sellers' cartel that the Panel focused on. Hence, the rules allowed for a restriction of competition in the import of termination services, and it may have been more natural for the Panel to focus on those restrictions. However, the Panel is, as usual, restricted to considering the claims put forward by the parties, and since the United States did not focus on the buyers' cartel, that was not within the scope of what the Panel could review.

The Panel's approach also has far-reaching consequences. Indeed, the Panel has effectively outlawed export cartels. This may be attractive from an economic perspective. Indeed, export cartels lead to the

${ }^{10}$ See WTO Doc. S/NGBT/W/3/Add. 14 of 21 October 1994. See also the Australian communication on scheduling for termination in services in WTO Doc. S/NGBT/W/16 of 10 November 1995. 
distortions that are associated with the exercise of market power (in terms of allocative and possibly productive efficiency). These distortions are also often considered significant from an empirical perspective (see, for example, Jenny 2003). The institutional consequences are, however, significant; for instance, a consequence of the Panel approach is that the exemption of export cartels in the United States under the Webb-Pomerene Act appears to be in contravention of the obligations of the United States under the GATS. One wonders whether the signatories of the GATS meant to impose such a discipline, given that the implementation of competition rules (including rules on export cartels) is not pursued further within the WTO, at least for the time being.

\subsection{Exports and imports of telecom services}

As indicated above, the sale of southbound international calls by US telecom suppliers to US subscriber cannot be seen as a mode-1 supply of services into the Mexican market to the extent that the buyers are located in the United States (the same territory as that of the supplier). This approach emphasizes the location of the party who pays for the service in order to distinguish between domestic and international transactions. However, a call could conceivably be seen as a service for which both the calling party and the receiving party are willing to pay, and the question of who pays for the service could be seen as a matter of convention. ${ }^{11}$ In this framework, a US operator that connects a US calling party with a Mexican correspondent is providing a service to the Mexican party. The US operator is effectively supplying a service to Mexican consumers, using US factors or production, so he can be seen as providing a cross-border supply under mode 1, as well as purchasing Mexican services (to terminate the call).

This raises two issues: first, it is apparent that the distinction between exports and imports of telecom services relies on the location of the party who pays for the services (the consumer being considered the one who pays). Still, neither the GATS (broadly speaking) nor the WTO case law seems to have singled out the identity of the party who pays to define the identity (and location) of the party who consumes a service. Second, one can only feel a little uncomfortable with a substantive distinction (which triggers the application of the GATS)

${ }^{11}$ This is the so-called "calling party principle" or CPP. 
that relies on a convention (namely, the convention that the calling party pays).

One can then wonder what the Panel's analysis would have been if the recipients of southbound calls had been considered consumers of the services provided by the US telecom operators. According to this approach, the conditions under which a US operator could buy the Mexican termination service would affect its ability to offer a service to Mexican consumers. Because the routing of the call to the border and the termination of that call in Mexico are a complement, a restriction on the export of termination services, for instance an export cartel that increased the price of termination, would increase the cost of supplying the service by the US operators and thereby reduce the amount of services sold to Mexican consumers (and their US correspondents). The export restriction would act as an import barrier. Accordingly, there may have been a case for preventing export restrictions under the GATS because of their potential effect on imports, for instance under a market-access provision. ${ }^{12}$ This logic, however, is not spelled out by the Panel.

\subsection{Mexico's concession: the routing requirement}

Having accepted that US firms were providing cross-border telecommunication services, the panel observed that, in its schedule, Mexico has committed to provide market access for such services, subject only to a routine requirement ${ }^{13}$ (that calls be routed to a Mexican operator with a concession).

Mexico, in its schedule of commitments, inserted a routing restriction according to which all international traffic would have to be routed through the facilities of an enterprise that had a concession. It then defined under what conditions a concession could be granted under Mexican law. In the Panel's view, in order to respond to the US claim, it would first have to assess the consistency of the routing restriction with Art. XVI.2 GATS (the legal basis invoked by the complainant).

${ }^{12}$ Of course, any restriction on exports that are used in the production of a commodity abroad for which there is an import demand will have that effect. But the strict complementarity between the two components of the call makes the effect sharper.

${ }^{13}$ In addition, the Panel observed that Mexico's commitment applies only to cross-border services supplied by facilities-based operators, and not by operators using capacity leased from another operator. 
The Panel ( $\S 7.80-7.86)$ makes a prima facie defensible argument ${ }^{14}$ distinguishing between facilities- and non-facilities-based trade and goes on to find that the Mexican routing restriction makes it clear that non-facilities-based carriers cannot supply telecoms services: a "facilities-based service operator" is a telecommunications service provider owning, as opposed to leasing, networks used to provide telecommunications services. On the other hand, "comercializadoras" (non-facilities-based) are in fact "resale-based service suppliers," leasing bulk-rate plant (i.e. transmission) capacity from facilities-based carriers and using that capacity to provide services to individual customers or groups of customers at prices high enough to make a profit, yet sufficiently below the equivalent rates of the facilities-based carriers to attract customers. Hence, in the Panel's view, the routing restriction is tantamount to telecom carriers having to interconnect with facilitiesbased carriers in Mexico, since interconnecting with non-facilities-based carriers is not an option.

Having decided this ${ }^{15}$ (i.e. that the United States could legitimately expect Mexico to honor its concession with respect to facilities-based suppliers), the panel next examined to what extent Mexico had honored its commitment under the TRP (and Section 5 of the Annex) to provide reasonable (i.e. cost-oriented) rates with respect to access pricing (interconnection).

Indeed, as discussed above, the full picture of Mexico's telecom commitments includes not only the routing restriction, but its

${ }^{14}$ There are many aspects of the argument, however, with which we disagree. For example, the Panel seems to adopt the idea that only limitations of the six types mentioned in Art. XVI.2 GATS can lawfully be entered into a schedule of concessions. However, the plain textual reading of Art. XVI GATS leads to the exact opposite outcome: (1) the expressions "terms" and "conditions" appearing in Art. XVI.1 GATS, which are not repeated in its $\S 2$, are terms distinct from the term "limitation" (which also appears in $\S 1$ ). Hence, in our view, $\S 2$ is only an elaboration of $\S 1$ with respect to "limitations," but that still additional "terms" and "conditions" could be lawfully inserted in a schedule. (2) Footnote 8 to Art. XVI GATS (actually to its $\S 1$ ), which clearly indicates that the movement of capital under mode 1 and (partially) under mode 3 must be allowed. But that would imply that a restriction on capital movements could be introduced with respect to modes 2 and 4 , although those restrictions do not fall squarely within any of the six measures in $\S 2$ of Art. XVI GATS. The Panel summarily discards such arguments by paying more attention to documents of ambivalent legal value (scheduling guidelines) rather than to the text of Art. XVI GATS itself.

${ }^{15}$ Mexico did not go down without a fight on this issue. In its view, the routing restriction made it impossible for any carrier to supply cross-border telephone services to customers 
obligations under the Annex and the TRP. It is also clear that the evaluation of the routing restriction was a passage obligé for the Panel: coming to a conclusion on the precise ambit of Mexico's commitments with respect to facilities-based service is the necessary first step toward establishing Mexico's obligation to guarantee cost-oriented rates. Had the panel, for example, concluded that Mexico had undertaken no commitments on mode 1 , the rest of the analysis would have been redundant.

\subsection{Applying the TRP to mode-1 supply of services}

Hence, the Panel saw the routing restriction as the basis for the additional interconnection commitments contained in the reference paper (Section 2). Given that the TRP does not explicitly mention interconnection with respect to cross-border services, the Panel then relies on various other means and contextual elements to evaluate whether it does indeed cover such types of interconnection. The Panel took the view that commitments under the TRP are applicable to international interconnection, ${ }^{16}$ i.e. in a transaction where the supplier of telecom services has no commercial presence in the market where it will supply the services at hand. In other words, the panel has indeed ruled that, with respect to mode 1 (cross-border), WTO Members have to abide by the TRP. ${ }^{17}$

The Panel made this finding despite the fact that the so-called regime of accounting rates had been explicitly excluded in the course of the negotiation, as expressed by the Report of the Group on Basic Telecommunications (15 February 1997). The regime of accounting

in Mexico, unless the foreign carrier was also established in Mexico and carried a concession. Hence, assuming that AT\&T also controlled a carrier in Mexico that had lawfully been granted a concession by Mexico, it could sell telephone services to customers in both the United States and Mexico. This point is probably not the strongest in Mexico's defense of the case: the routing restriction imposed the obligation to route incoming calls to facilities-based carriers, which meant that anyone, and not only those having invested in Mexico, could, in principle, route calls to facilities-based operators in Mexico. Hence, Mexico's defense did not address the heart of the issue here, that is, under what conditions such transactions would take place.

${ }^{16}$ We find no evidence in the negotiating history where this term (i.e. "international interconnection") has been used. For a very comprehensive of the context surrounding the negotiating history of the TRP, see Bronckers and Larouche (2005). The authors provide a very detailed account of the circumstances surrounding the negotiation and of the regulatory framework as such.

${ }^{17}$ Of course this obligation binds only those WTO Members that adopted the TRP. 
rates is a regime that was widely used by different countries before deregulation, such that the price for termination of international calls was determined only on the basis of net flows, typically between historic operators and on the basis of agreed rates. The regime implemented by Mexico under ILD rules can be seen as a variation of an accountingrate regime that accommodates the presence of several operators. The Panel, however, found that the Report of the Group on Basic Telecommunications referred only to accounting-rate regimes that violate MFN provisions.

We find this approach hard to sustain. The TRP was negotiated and conceived to address a situation where telecom services would be supplied through commercial presence. For reasons having to do with the fact that (a) not all WTO Members had, at the time of the advent of the Telecoms Agreement, adequate competition statutes in place, and (b) because some WTO Members had already demonopolized trade in services and hence obligations would de facto be assumed by private entities, it was felt that a contractual arrangement was necessary to make sure that telecoms liberalization would be effectively pursued. ${ }^{18}$ This is the role of the TRP.

Both the text and the concessions assumed under the TRP make it clear that it was conceived to address a mode-3 supply of service and nothing else.

Interconnection (access pricing) is the centerpiece of the TRP. According to $\S 2.2(\mathrm{a})$, WTO Members must provide interconnection:

under ... terms, conditions ... and rates and of quality no less favourable than that provided for its own like services ...

The term "like services" has consistently been interpreted by WTO Panels dealing with GATS-related issues from the consumers' perspective: to the extent that consumers treat two services interchangeably, the services at hand will be considered like. ${ }^{19}$ For consumers, of course, it is highly unlikely that a phone call between two points in Mexico City and a phone call from Mexico City to Athens, Georgia, are interchangeable. Viewed from the supply side, the outcome does not differ: for Telmex, for example, it is impossible to establish comparability between the two phone calls mentioned above, since Telmex will need to

${ }^{18}$ See Hoekman et al. (1998) and Mavroidis and Neven (2000) on this issue.

19 See for example, the Panel and the Appellate Body(AB) reports on EC - Bananas (WTO Doc. WT/DS/27). 
purchase termination services from a US carrier, the cost of which does not necessarily have to correspond to that charged by Mexican carriers when terminating calls. Moreover, it could very well be the case that the United States has entered no such commitments at all; hence, comparability will never be established. The only case where comparability can always be established is when we compare a phone call between two points in Mexico City supplied by Telmex and the same phone call supplied by, for example, AT\&T.

The application of the TRP to mode-1 exports raises further issues. For instance, it is hard to make sense of the requirement with respect to universal service ( $\S 3$ of the TRP) in the case of mode- 1 exports. It would effectively amount to a requirement for Mexican telecom operators to sell termination services to foreign suppliers so that all foreign subscribers can call Mexico. This would be absurd, as Mexican suppliers have no way to ensure that every foreign subscriber can call Mexico, as this is largely determined by the policy of foreign suppliers.

Consider further $\S 1.1$ of the TRP, which informs the rest of the document as to the nature of the obligations assumed. It reads:

Appropriate measures shall be maintained for the purpose of preventing suppliers who, alone or together, are a major supplier from engaging in or continuing anti-competitive practices.

Assuming that it is applicable to export transactions, this provision would ipso facto mean that some national competition laws would have to be drastically amended. Typically, competition statutes use domestic consumer welfare as the proxy to distinguish between what is and what is not permissible in terms of market behavior. Cartelizing export markets is not much of a concern, since they involve higher profits for domestic firms (at the expense of foreign buyers) and cannot be expected to hurt domestic consumers. A good example is offered by the US competition laws: the US Webb-Pomerene Export Trade Act of 1918, for all practical purposes, exempts US export cartels from antitrust persecution by US authorities. Has the United States, by agreeing to telecom liberalization under the GATS, ipso facto agreed to abolish this act? This would be a far-fetched conclusion indeed.

Once again, the commitments under $\S 1$ make perfect sense when viewed as commitments regarding behavior in the domestic market. 
It is not only the text, but also the manner in which the text has been understood by WTO Members when scheduling their commitments, that lends intellectual support to this line of thinking: we found not one single export commitment (e.g. selling termination services irrespective of the commercial presence of the foreign carrier in the domestic market $)^{20}$ in the schedules of concessions of those WTO Members that undertook commitments in the field of telecoms. Hence, subsequent practice, an interpretative element mentioned explicitly in Art. 31 of the Vienna Convention on the Law of Treaties (VCLT), ${ }^{21}$ leads to the same conclusion.

The Panel's attitude is indeed problematic here. By contrast, were one to understand the obligations imposed by the TRP as limited to a mode-3 type of telecom supply (commercial presence), then the whole document makes eminent sense. It essentially amounts to an obligation to impose minimum competition-law requirements to incumbents, in full respect of the territoriality principle conferring jurisdiction.

The Panel is thus right only if the requirement to supply services at cost-oriented rates under $\S 2.2(\mathrm{~b})$ of the TRP is interpreted outside its context (i.e. without taking any account of all other obligations mentioned in the TRP). This is not, however, a mode of interpretation consonant with Art. 31, on which, the panel, paradoxically, relied.

Overall, we find good reasons to think that the disciplines embedded in the TRP should not be applied to the provision of mode- 1 crossborder services. First, this implies that even if the case before the Panel concerned termination services supplied on a cross-border basis by Mexican carriers to US customers, the panel should still have declined to apply the TRP and should have dismissed the case. Second, it also implies that if the Panel had been confronted with another claim by the United States, namely that Telmex was exercising buyer power in the purchase (imports) of termination services from the United States (for northbound calls), it should also have dismissed the case.

${ }^{20}$ In fact, if at all, the negotiating record seems to suggest that WTO Members did not wish, for some time at least, to rock the boat with respect to such transactions. This is what the agreed Memorandum on Accounting Rates essentially boils down to.

${ }^{21}$ From early on, when ruling on the first dispute submitted to it, the $\mathrm{AB}$ made it clear that the WTO judge has no choice but to follow the VCLT when interpreting the WTO agreement, and this by virtue of Art. 3.2 DSU. 


\section{Cost-oriented rates}

In what follows, we assume that the interconnection provision of the reference paper applies to the international termination of calls and review the Panel's approach in the implementation of this provision.

The Panel first inquired whether Telmex could be considered a "major supplier." The Panel acknowledged that a relevant market had to be delineated in order to perform this assessment and concluded that the relevant market was the market for the termination of calls into Mexico. Telmex was found to be a major supplier in light of the fact that it could "affect the terms of participation" in the market. The Panel then examined whether termination rates were cost-oriented. The Panel discussed what cost-orientation may entail and, relying again on supplementary sources, found that long-run average incremental cost could be seen as an appropriate benchmark. The Panel indicated (§ 7.177):

We find that the increasing and wide-spread usage of incremental cost methodologies among WTO members supports the interpretation of the term "cost-oriented" as meaning the cost incurred in supplying the service, and the use of long term incremental cost methodologies, such as those required in Mexican law, is consistent with this meaning.

The Panel then reviewed the evidence submitted by the United States, in particular the evidence showing that the price for termination of international calls was much higher than the price for terminating calls within Mexico, even if one allows for the additional cost incurred in the international gateway. Taking these domestic termination rates as an appropriate benchmark for what long-run incremental cost may be, and having observed that international rates were "substantially" higher, the Panel concluded that the international rates were not cost-oriented.

From an economic perspective, the Panel's focus on properly defining the relevant market is welcome; by so doing, the Panel reduces the risk that it may find that a firm alone or together with others is a "major supplier" in a market in which market power could not be extracted. Unfortunately, the Panel did not spell out in detail how the relevant market should be delineated, simply referring to the importance of demand substitution.

As indicated above, the Panel found that the termination of international calls is a relevant market because buyers cannot 
undertake an international call without termination (there is no substitute). This analysis raises at least two issues:

First, the Panel did not inquire about the possibility of substitution through calls in the opposite direction; faced with an increase in termination charges, which is passed on to the final US consumers, it is possible that US buyers will drastically reduce their demand and convince their Mexican correspondents to call them. This approach, which has been discussed in the telecom literature, ${ }^{22}$ suggests that southbound calls may be substitutable for northbound calls. ${ }^{23}$ This pattern may be important among so-called closed user groups. If the substitution is large enough (at the level of the overall market and not only for some closed user groups), it may imply that there is no relevant market for the termination of calls into Mexico, but rather a market for point-to-point services between Mexico and the United States. This issue is not discussed by the Panel. ${ }^{24}$

Second, one can wonder whether the Panel should not have made a distinction between the international switch (the interconnection itself) of the incoming calls and the termination in the domestic network. These two components can, in principle, be unbundled, and, in fact, they are, when gateway operators transfer excess calls to other long-distance carriers. So, the Panel should probably have distinguished between the two relevant markets. If it had done that, it obviously would have found that Telmex and the other long-distance carriers were major suppliers in both. However, this approach suggests that the Panel could have raised another concern with respect to the termination offered by Telmex and other suppliers, namely the extent to which it was unbundled (since Art. 2.2(b) stipulates that interconnection should be "sufficiently unbundled").

Having delineated the market, the Panel considers, as indicated above, whether Telmex is a major supplier and whether rates are costoriented. This discussion is somewhat odd under the circumstances of the case; given that the regulation will lead to prices that will mimic monopoly prices, a discussion of whether Telmex is a major supplier would appear to be somewhat besides the point (the belabored

${ }^{22}$ See for instance, Hausman (2002).

${ }^{23}$ If northbound calls are taken as a substitute for southbound calls, the distinction between imports and exports of basic telecom services disappears.

${ }^{24}$ Even though it was apparently raised by Mexico, see Sidak and Singer (2004) on this issue. 
discussion of Telmex's market share is, from that perspective, a little surrealistic). Similarly, to the extent that, among all market structures, monopoly will lead to prices that least reflect costs, the discussion of whether rates set by Telmex are cost-oriented may not be necessary.

It is, however, worth commenting briefly on the Panel's analysis with respect to cost orientation, as it may establish some precedent. ${ }^{25}$ First, as indicated above, the wording of Art. 2 induces the Panel to find reference in the field of regulation; the Panel considers as a benchmark the level at which prices could be regulated if termination is considered as a bottleneck facility. The Panel draws an immediate analogy to domestic interconnection and the access prices to local networks, which are often bottleneck facilities. The Panel also finds some guidance from the recommendations of the International Telecommunications Union with respect to the determination of accounting rates, i.e. when there is a single international gateway - which is therefore a bottleneck facility. However, these references are certainly not the only useful references, given that international termination is somewhat unlikely to be a bottleneck facility (as long as access to the last mile is regulated).

Second, assuming that the regulated rates provide useful guidance, it appears that the choice of long-run average incremental cost as a proper benchmark and the presumption that the same rates should be applied for a given service regardless of the users can be discussed. The reference to long-run incremental cost (a forward-looking concept) can be recommended only if there is no issue with respect to the financing of the existing infrastructure, or in other words, when there is no risk of important stranded costs. In addition, in the presence of public-service obligations in some segments, the use of long-run average incremental costs cannot be recommended. It does not seem that the panel should prejudge the issue of whether Mexico should be imposing some public-service obligations. ${ }^{26}$

Moreover, it is not clear that rates should not be differentiated across segments; there is a great deal of literature on the regulation of access prices (see for instance, Armstrong [2002], for a survey) and this

${ }^{25}$ The approach followed by the Panel to define a "major supplier" is discussed in the next section.

${ }^{26}$ Of course, in the case at hand, it is not clear why the Mexican regulator should distribute rents to long-term carriers that are not assuming public-service obligations. Only Telmex is arguably assuming such obligations, in particular with respect to the provision of a local network in remote areas. 
literature emphasizes three concerns, namely: (i) the need to reflect the marginal cost of providing access; (ii) the need to finance the infrastructure (in particular in the presence of large fixed and common costs); and (iii) the provision of appropriate incentive for entry (when entrants operate with lower margins than the incumbent, they may profitably enter even though they are less efficient). The optimal access prices will then typically balance the allocative inefficiency that is induced by an increase in access charges in excess of marginal cost and the improvement in productive efficiency that such an increase induces by limiting the excess entry. One of the main insights of these pricing schemes is, however, that the markup over marginal cost should vary among market segments; markups should be higher in markets where the elasticity of demand is low (in the spirit of Ramsey prices).

To be fair, it is true that few regulatory authorities have found it practical to calibrate access charges according to demand elasticities, so that access charges often reflect average costs (for some hypothetical use of capacity). Still, adopting a suboptimal practice as a legal norm in the context of the WTO is not necessarily appropriate, as regulators' ability to calibrate access charges may improve over time. Furthermore, if the reference to average cost is commonly accepted among regulators in developed countries, it is not clear whether this practice is equally attractive for developing countries (see for instance, Laffont 1998).

\section{Abuse of dominant cartels?}

Finally, the Panel considered whether Mexico had maintained appropriate measures to prevent "suppliers who are, alone or together a major supplier from engaging in or continuing anti-competitive practices."

In deciding whether Telmex was alone a major supplier (in the context of the interconnection discussed in the previous section), the Panel simply used the definition provided by the reference paper. In particular, the fact that Telmex could materially affect the "terms of participation in the market with respect to price" was sufficient to conclude that it was a major supplier. Given that Telmex was, following the ILD rules, in charge of negotiating common prices for termination, this seems relatively uncontroversial. The Panel further found that Telmex and the other operators were together also a major supplier, simply because the implementation of the ILD rules involved the fixation of common prices by all gateway operators. 
Clearly, Telmex and the other gateway operators had the ability in the context of the ILD rules to materially affect prices.

The Panel then defined what was meant by anticompetitive practices. Its first source of inspiration was the dictionary, from which it learned that an anticompetitive practice was "an action that lessens rivalry or competition in the market" (§ 7.230). From the (nonexhaustive) list of anticompetitive practices provided by the reference paper, the Panel concluded that, since "anti-competitive crosssubsidization" was listed, pricing actions could be a concern (§ 7.232). The Panel further observed that, since the definition of what was a major supplier included its ability to "materially affect prices," anticompetitive practices should focus on prices (§ 7.233). That was enough for the Panel to conclude that horizontal price-fixing should be considered an anticompetitive practice in the reference paper. Final confirmation of its approach was given by the Havana Charter, which recognized that price-fixing could adversely affect international trade; and the fact that the Organisation for Economic Cooperation and Development (OECD) had adopted a recommendation calling for strict prohibition of cartels; the fact that, in the WTO working group on trade and competition policy, "reference had been made to the pernicious effect of cartels"; and the fact that, in the competition legislation of certain Members, anticompetitive practices included price-fixing.

The approach followed by the Panel is not convincing. The fundamental, quintessential obligation of all WTO adjudicating bodies is not to undo the balance of rights and obligations as struck by the negotiating partners (Art. 3.2 DSU). To put it bluntly, panels cannot invent obligations, given the institutional risk that this would entail. In case of legitimate doubt, it is probably more appropriate for the judge to raise the issue and leave the decision to the principals (die Herren der Verträge).

The WTO Members decided not to undertake any explicit obligations vis-à-vis their partners regarding cartels. With respect to cartels, WTO Members have adhered to a contractual arrangement in which they must consult when a complaint to this effect has been launched (Art. IX GATS). They accepted nothing more beyond this obligation. This provision is evidence that the negotiating partners were indeed aware of the danger that restrictive business practices originating in cartels might present for trade in services. The non-inclusion of 
such practices in the TRP was thus a matter of choice rather than a simple omission. ${ }^{27}$

In its chapeau, $\S 1.2$ of the TRP also makes it clear that what follows is an indicative list of restrictive business practices (RBPs). ${ }^{28}$ It then enumerates three anticompetitive practices, and cartels are not included. The Panel acknowledged this point as well (§ 7.231).

An indicative list is a clear-cut case of an incomplete contract that the judge will be called upon, eventually, to complete. The inclusion of certain practices in the indicative list of $\S 1.2$ of the TRP can be seen as reflecting the judgment of the contract's authors with respect to the prevalence of type-II errors (false negatives), if the practice is not systematically addressed (i.e. the possibility that if such a practice is not constrained, it will often be harmful). By contrast, the fact that some practice is not included must reflect the judgment that, if not constrained, such a practice will not be systematically harmful. This perspective has clear implications for the standard of review that should be applied in case an additional practice is included in the list. Moreover, the identity of the practices included in the list could give guidance to the judge as to which transactions could be added to the existing list. ${ }^{29}$

Had the Panel approached the list of $\S 1.2$ in this manner, it would have noticed that the first and second examples in the indicative list cannot concern cartel-type behavior. At the same time, while with respect to the third example cartel-type behavior cannot be excluded, it is highly unlikely that the drafters of the treaty wanted to sanction such behavior through this example.

The Panel chose to disregard this avenue and instead build its case that cartel-type behavior was punishable through the TRP by looking at the Mexican legislation, the Havana Charter, and some OECD documents. However, because the Havana Charter never entered into force, its legal value is largely symbolic (by virtue of Art. XXIX GATT), and the OECD documents are non-binding contracts. The fact that Mexico

${ }^{27}$ Concurring on this issue, Marsden (2004).

28 We use the term "RBPs" as equivalent to the term "anti-competitive practices" appearing in the TRP.

29 From this perspective, it is also useful to note that the reference paper imposes a discipline only to particular firms, namely those that are "large" (dominant). A discipline with respect to cartels typically applies to all firms and hence does not fit well in this context. Indeed, most competition regimes rely on this distinction and have separate provisions for cartels (e.g. Art. 81 ECT) and the abuse of dominance (Art. 82, ECT). 
punishes cartels through its domestic legislation is simply irrelevant: as stated above, the United States punishes cartels when they cartelize the US economy, but does not do so when they cartelize the world. What matters is the nature of obligations assumed under the WTO. ${ }^{30}$

Arguably, provisions like Art. 82 ECT on the abuse of dominance (or the analysis of monopolization under Section 2 of the Sherman Act) are also sources from which the panel should have sought some inspiration: in particular, the TRP requires a threshold finding that firms are "major suppliers" before practices may be evaluated, and in that respect, it is similar to Art. 82 ECT, in which dominance must first be established before an analysis may be undertaken as to whether observed conduct constitutes an abuse. In addition, as discussed above, the TRP was conceived as an instrument to control the conduct of historic incumbent operators, a task that is undertaken under provisions like Art. 82 ECT. $^{31}$

Under provisions like Art. 82 ECT (or Section 2 of the Sherman Act), a distinction is usually drawn between exploitative and exclusionary practices. $^{32}$ The former designation refers to the exploitation of market power at the expense of buyers and includes business practices like price discrimination, in addition to, the profitable price increases permitted by the firms' own-demand elasticities. The latter refers to business practices aimed at foreclosing or marginalizing competitors and includes predation as well as other practices like tying and bundling.

Exploitative abuses are normally not pursued under Section 2 of the Sherman Act because preventing firms from exploiting the market power that the successful development of their business has conferred on them might reduce the very incentive to develop that business and compete in the first place. Similarly, the European Commission (EC) and European Union (EU) courts have been very reluctant to sanction exploitative abuse. From that perspective, the Panel's approach, which is sanctioning the mere exploitation of market power, appears to be rather bold.

${ }^{30}$ We do not equate the WTO with a self-contained contract, but we find it implausible to assume that all national law is binding on WTO Members anyway, even in the absence of specific international commitments to this effect.

${ }^{31}$ This is acknowledged by the panel (at $\S 7.237$ ): "members agreed ... to implement a pro competitive regulatory framework designed to prevent continued monopoly behavior, particularly by former monopoly operators, and abuse of dominance by these or any other major suppliers."

32 See, for instance, or Fox (2002). 
There is another dimension in which the panel's approach appears to diverge from the antitrust practice. Art 82 ECT allows for the fact that "one or more undertakings" may hold, and abuse, a dominant position. The practice has focused on single-firm dominance and unilateral conduct as potentially abusive, but the EU has also developed the concept of collective dominance, in narrow circumstances. A similar approach is followed under Section 2 of the Sherman Act. Admittedly, the limited use of collective dominance that is found in the EU and the United States is partly due to the fact that both antitrust regimes rely on different provisions (Art. 81 and Section 1) in order to sanction conduct involving several firms, and in particular, price-fixing. Of course, unlike antitrust authorities, the panel could not rely on another provision to sanction horizontal price-fixing, which is clearly present and presumably damaging in the present case. And the prospect that sanctioning exploitative abuse may discourage investment and reduce the incentive to compete hardly matters in the presence of a cartel.

Still, it is striking that the Panel did not approach the case from the perspective of collective dominance. Such an approach may have had some merit. Indeed, structural links among companies would be easy to show in a case like this, where it is the legislator that in fact established the cartel. On the other hand, the abuse-of-dominance scenario should not be discarded altogether: in this case, there is one leading player (Telmex) that has by law received assurance of noncompetition from other minor players (since prices will be set at an industry level). Depending on the specifics of the case, on which we have no additional information, it could be that this law contributes to abuse by the dominant player.

There is a final issue that deserves comment, namely whether practices that are required under domestic law can be sanctioned by the TRP. Mexico, and the EU as a third party, argued that this is not the case; according to them, if a Member decides not to allow competition in a particular segment of the telecommunications sector, there is simply no scope for an anticompetitive practice. Following the EU submission, "it is not possible to restrict competition where competition is not allowed." The United States disagreed, naturally arguing that, if Mexico were free to introduce legislation that compels firms to engage in anticompetitive practices, the TRP would be meaningless. The issue is thus whether the TRP should be seen as a constraint on regulation or a constraint on additional measures (for instance, competition policy) that may be taken, given that regulation takes precedence. 
This Panel found that the TRP acts as a constraint on regulation so that business practices that are required by domestic law can be found to be anticompetitive under the TRP. In so doing, the Panel effectively set aside the so-called "state doctrine" in antitrust. According to this doctrine, business practices that are required by states (domestic or foreign) fall outside the reach of antitrust rules. Such a doctrine may be justified when competition law is implemented at the same time as other laws promulgated by the same government (even if the implicit precedence given to other laws could be disputed). In this case, one authority decides according to its own preference how two of its instruments should be managed. But it is hard to justify the doctrine in the context of the TRP, which results from an international agreement, relative to domestic regulation: these are different authorities, and it is not clear why the domestic authority should be given the right to manage the implementation of domestic regulation and the international agreement. Indeed, the opposite would seem to be appropriate, given that the international agreement is a constraint on the domestic government to start with. Hence, it does indeed seem appropriate to reject the state doctrine.

\section{Conclusion}

The Panel's decision in this case had the effect of prohibiting a price-fixing agreement that was in all likelihood damaging in terms of overall welfare. This agreement was clearly improving welfare in Mexico (increasing the profit of gateway operators) at the expense of the US firms and consumers. From this perspective, the outcome can be seen as satisfactory.

However, the Panel achieved this result through a sequence of interpretations and assessments that seems controversial: first, by accepting a transaction such as the one under dispute as a mode-1 supply of services, the panel ipso facto accepted that a supply of service where the supplier of the service and its consumer are physically in the same territory is also covered by commitments under mode 1 . This conclusion, however, is unwarranted in light of the definition of mode 1 , the concessions made under mode 1 , and the willingness of WTO Members to ensure that mode 1 will have a horizontal meaning irrespective of the service to which it applies. Our analysis still highlights the difficulty in distinguishing exports and imports in the field of telecommunications and the importance of additional guidance 
in this matter. Second, even assuming that the dispute before the panel was presented as a dispute concerning the conditions under which Mexico would supply termination services under mode 1 to the US carriers, the Panel should not have assumed that the TRP was applicable to such transactions. A careful, contextual reading of this document supports the view that it covers supply of services under mode 3 only. This is not to say that Mexico could not have assumed similar obligations for its sales of termination rates to US carriers with no commercial presence in the Mexican market. However, in the present case no such commitments were entered into. This is a factual issue, and the Panel, by making a legal issue out of it, undid the balance of rights and obligations as struck by the negotiating partners. Third, even assuming that the TRP applies, the Panel should not have concluded that interconnection rates were not "reasonable, cost-oriented rates" on the basis of the evidence before it. The Panel took a rather definite view on regulatory principles which involve complex and controversial issues. This ruling may thus have important systemic consequences. Fourth, even assuming that the reference paper applies, the Panel should not have concluded that cartels are punished by the TRP, knowing in addition that this approach was not necessary for it to reach its finding on this score.

Overall, the Panel's review of the competition-law component of this dispute leaves much to be desired. Based on the evidence before it, the Panel would have been on much safer ground had it requested additional information. Indeed, Art. 13 DSU empowers panels with very important discovery competencies. Sadly, this panel refused to make use of this institutional facility. This is regrettable, especially in a case like this, where recourse to expertise, in light of the current endowments of the WTO, is especially necessary.

\section{References}

Armstrong, M. (2002). The theory of access pricing and interconnection, In The Handbook of Telecommunications Economics, Caves, et al., eds. Chapter 8 Vol. I., Elsevier Science: North Holland, pp. 295-384.

Bronckers, M. and Larouche, P. (2005). The GATS Mimeo.

Fox, E. (2002). What is harm to competition? Exclusionary practices and anticompetitive effects, Antitrust Law Journal, 70: 371-413. 
Hausman, J. (2002). Mobile Telephone. In Handbook of Telecommunications Economics, Caves, et al., eds. Vol. I, Elsevier Science: North Holland, pp. 563-604.

Hoekman, B., P. Messerlin and Mavroidis, P.C. (1998). Regulation, competition policy and market access negotiations: lessons from the telecommunications sector. In Competition and Trade Policies, Einar Hope ed. Routledge: New York, pp. 115-139.

Jenny, F. (2003). International Cooperation on competition: myth, reality, and perspective, Antitrust Bulletin, 48: 973-1003.

Laffont, J.-J. (1998). Competition, information and development, Annual World Bank Conference on Development Economics, pp. 237-268.

Mardsen, P. (2004). Trade and competition. WTO decides first competition case - with disappointing results, Competition Law Insight, 16(3), pp. 3-9.

Mavroidis, P.C. and Neven, D.J. (2000). The WTO agreement on telecommunications: it's never too late. In The Liberalization of State Monopolies in the European Union and Beyond, D. Geradin, ed. Kluwer: London, pp. $307-318$.

Sidak, G. and H. Singer. (2004). Überregulation without economics: the world trade organization's decision in the US-Mexico arbitration on telecommunication services Mimeo. 